\title{
Aisthesis
}

Firenze University Press

www.fupress.com/aisthesis

OPEN ACCESS

Citation: L. Sala(2021) Systematicity, Purposiveness, Necessity: from the transcendental deduction of the ideas to the transcendental deduction of the principle of purposiveness of nature. Aisthesis 14(2): 41-53. doi: 10.36253/Aisthesis-12755

Copyright: (c) 2021 L. Sala. This is an open access, peer-reviewed article published by Firenze University Press (http://www.fupress.com/aisthesis) and distributed under the terms of the Creative Commons Attribution License, which permits unrestricted use, distribution, and reproduction in any medium, provided the original author and source are credited.

Data Availability Statement: All relevant data are within the paper and its Supporting Information files.

Competing Interests: The authors have declared that no competing interests exist.

\section{Systematicity, Purposiveness, Necessity: from the transcendental deduction of the ideas to the transcendental deduction of the principle of purposiveness of nature ${ }^{1}$}

\author{
LORENZO SALA \\ Universität Trier \\ sala@uni-trier.de
}

\begin{abstract}
In this paper I argue for a strong continuity between the transcendental deduction of the principle of purposiveness of nature and the transcendental deduction of the ideas from the first critique. On these grounds, I provide an interpretation of the transcendental deduction of the principle of purposiveness of nature in which I argue that: 1) the necessity of the principle of purposiveness of nature does not derive from its role in solving some specific philosophical problem (e.g. that of induction) but from its relation to a cognitive goal; 2) the representation of nature as conforming to the maxims of judgement is a direct, immediate consequence of a certain cognitive goal (in particular, of what is researched in the empirical investigation of nature; 3 ) that the necessity of the empirical laws mentioned by Kant in the transcendental deduction of the principle of purposiveness of nature is not so much their nomic necessity, but their necessity as consequences of higher laws.
\end{abstract}

Keywords: Transcendental deduction, Principle of purposiveness of nature, Appendix to the transcendental dialectic, Nomic necessity, Critique of the power of judgement.

In the literature on Kant's third Critique, there is a widespread tendency to interpret the transcendental deduction of the principle of purposiveness of nature as if it was aimed at solving the particular epistemological problem in light of which the principle in question is interpreted, be this the problem of induction (e.g. Allison [2001]), of the necessity of empirical laws (e.g. Teufel [2017]), or anything else. For this reason, the transcendental deduction of the principle of purposiveness of nature is interpreted in analogy to the transcendental deduction of the pure concepts of the understanding from the

\footnotetext{
${ }^{1}$ This work was written with the support of the Core Fellowship at the Institute for Advanced Study at Central European University. I wish to express my gratitude to the whole staff for their precious support.
} 
first Critique, where Kant begins from some representations' (i.e. the categories) disputed claim to objectivity and then vindicates this claim by showing that these representations are necessary for having an experience of objects. Likewise, in the third Critique Kant would provide an argument that shows that to represent nature as purposive, whatever means, is necessary for something else, be this «systematic scientific knowledge» (Guyer [1997]: 38), the formation of empirical concepts (e.g. Ginsborg [2015]) or something else.

In contrast to this interpretative tendency, in this article I argue that the principle of purposiveness of nature and its deduction are best understood as following the same logic that was at play in the genesis and the deduction of the transcendental ideas in the first Critique. There, instead of starting from some disputed claim to objectivity and vindicating it, Kant first begins by considering a certain research-activity of reason, taken as a fact, and then shows how to engage in this research activity immediately amounts to represent nature in a certain way (in the case of the first Critique, according to ideas). Although this does not imply that nature actually is so determined, this does not render illegitimate to proceed according to such a representation of nature in our research (i.e. as if nature were so determined), so that the question of the legitimacy of such a way of representing nature is nonetheless settled. To interpret the transcendental deduction of the principle of purposiveness of nature as embodying a similar logic, I contend, provides a vantage point not only for making sense of its text, but also in relation to the much-debated issue of what kind of necessity is at stake when, in it, Kant refers to the necessity of the particular empirical laws. In particular, contrarily to what is most commonly argued (e.g. Teufel [2017]; Guyer [2003]: 287-288), the necessity Kant is referring to is not so much the nomic necessity of these laws, but their necessity as consequences of more general laws.

To substantiate these claims, I am going to proceed as follows. In the first section, I am going to consider Kant's account of the origin of transcendental ideas in the activity of producing syl- logisms. In particular, I will illustrate how to systematise our cognitions amounts in fact to represent things in a certain way: 1) as in relation to the unconditioned and 2) according to what Kant will later call the "maxims of the power of judgement» (Kant [1790]: 182; 69). On these grounds, in the second section, I will consider the transcendental deduction of the ideas that one finds in the Appendix to the Transcendental Dialectic. I will show how, in it, the fact that a certain way of representing things (i.e. according to ideas) is the result of a certain a cognitive goal reflects on its justification (that is, how it legitimates their regulative use). Against this background, in the third section I am going to show how, like ideas with syllogism, also the representation of nature as purposive is the correlate of a certain research activity (in particular: of the search of universals for given particulars that Kant calls reflective judgement). In this way, I will explain also why, for Kant, to represent nature as purposive for our cognitive faculties means to represent it according to the maxims of judgement. Building on these results, in the fourth and last section I will provide an in-depth analysis of the transcendental deduction of the principle of purposiveness of nature. In this way, I will show how the kind of necessity of the empirical laws of nature on which Kant's argument hinges is their necessity as logical consequences of higher laws (and not so much their nomic necessity); secondly, I will explain how a certain cognitive goal can ground and justify a certain way of representing nature, albeit only for a regulative use.

\section{ON THE ROLE AND THE ORIGIN OF THE IDEAS IN THE FIRST CRITIQUE}

In the Critique of pure Reason, Kant deals with what he will later call «maxims of the power of judgement» (Kant [1790]: 182; 69) in the Transcendental Dialectic, and specifically in its Appendix. Were in the Critique of the power of Judgement he takes these maxims to be the expression of the principle of purposiveness of nature (Kant [1790]: 184; 71), and links them to the Urteilskraft, in the 
Critique of pure Reason he links the very same maxims to reason (Vernunft) and its ideas. In both cases, Kant affirms that these maxims are linked to a certain way of representing nature itself, and in particular as systematic in some sense: in the case of the Critique of the power of Judgement $(K U)$, nature is represented as purposive for our cognitive faculties, in the Critique of pure Reason $(K r V)$, as if its unity was grounded in the objects of the ideas (e.g. all the psychological phenomena as manifestations of a simple substance, the whole of nature as created by God, etc.). With respect to this feature, the $\mathrm{KrV}$ is easier to interpret than the $K U$ : in the first, Kant writes more extensively about the reason why, in our empirical enquiry, we come to (and need to) represent nature itself as having a certain sort of systematic unity.

A good part of this explanation is not to be found in the Appendix to the Transcendental Dialectic, but instead in the Introduction of the Transcendental Dialectic: it is here that Kant explains how ideas (as representations of certain objects) originate in the role that reason plays in cognition. Specifically, like he did in the Analytic for the understanding and its concepts (the categories), Kant begins from the definition of reason that derives from its logical use, and proceeds from it to explain the origin of the ideas. Reason is first defined as the "faculty of drawing inferences mediately» (Kant [1781/1787]: A299/B355), i.e. syllogising, and then as «the faculty of the unity of the rules of understanding under principles» (Kant [1781/1787]: A302/B359).

The connection between these definitions can easily be understood by looking at one of Kant's definitions of principle - to be found in these very same pages - which is directly bound to the notion of syllogism:

The term principle is ambiguous, and commonly signifies only a cognition that can be used as a principle even if in itself and as to its own origin it is not a principle. Every universal proposition, even if it is taken from experience (by induction) can serve as the major premise in a syllogism. [...] Thus, every syllogism is a form of derivation of a cognition from a principle, for the major premise always gives a concept such that everything subsumed under its condition can be cognized from it according to a principle. Now since every universal cognition can serve as the major premise in a syllogism, [...] these propositions can, in respect of their possible use, be called principles. (Kant [1781/1787]: A300/B356-7)

In line with the logical terminology of his times, principle is defined in functional terms, i.e. as the proposition functioning as a major premise in a syllogism ${ }^{2}$. For instance, in the syllogism «all humans are mortal, all Athenians are humans, ergo all Athenians are mortal», "all humans are mortal» is the principle, and "human» is what Kant calls the condition. Precisely for its functional nature, it is clear that this definition does not concern the specific features of judgements in isolation, so that any universal judgement can be a principle in this sense, inasmuch as it has a certain role in a syllogism.

With this in mind, one can easily understand the definition of reason as «the faculty of the unity of the rules of understanding under principles» (Kant [1781/1787]: A302/B359) ${ }^{3}$. Indeed, Kant takes reason to be not only responsible for drawing inferences when the principles are given, but also for the opposite activity, i.e. bringing various judgements back to another judgement - their principle - by finding the appropriate condition. For instance, by finding the condition that makes (e.g.) Athenians, Spartans and Thebans mortal into their human nature, the judgements "Athenians are mortal», «Spartans are mortal» and «Thebans are mortal» are unified under the principle «all humans are mortal». Both in this case

\footnotetext{
${ }^{2}$ See, for instance, Meier’s definition of syllogism: «\$356. That judgment which is derived from others in a rational inference is the conclusion (conclusio, probandum, principiatum). But those judgments from which the conclusion is derived are the premises (praemissae, data, sumtiones, principia)» (Meier [2016]: 120).

${ }^{3}$ Kant's references to the rules of the understanding is due to the fact that, in general, Kant takes concepts to be rules (see, for instance, Kant [1781/1787]: A132/B171). On Kant's understanding of concepts as rules, see Vanzo (2012): 187-189.
} 
and when we draw an inference, we not only obtain a new cognition (either of the conclusion, when the principle is given, or of the unity of more cognitions, when it is the principle which is discovered): we also gain an insight into the (conditioned) ${ }^{4}$ necessity of the judgements that figure as conclusion - for instance, Athenians necessarily are mortal inasmuch as they are human ${ }^{5}$.

Together with the activity of drawing inferences from given judgements, the unification of cognitions under higher principles is what Kant calls the logical use of reason, and it is in relation to it that one is to understand both 1) the production of ideas (called by Kant real use of reason) and 2) the necessity of representing objects themselves (nature) in a certain way. The link between these elements is to be found in a passage from the Introduction to the Transcendental Dialectic, where one reads:

Reason in its logical use seeks the universal condition of its judgment (its conclusion), and the syllogism is nothing but a judgment mediated by the subsumption of its condition under a universal rule (the major premise). Now since this rule is once again exposed to this same attempt of reason, and the condition of its condition thereby has to be sought (by means of a prosyllogism) as far as we may, we see very well that the proper principle a of reason in general (in its logical use) is to find the unconditioned for conditioned cognitions of the understanding, with which its unity will be completed. But this logical maxim cannot become a principle of pure reason unless we

\footnotetext{
${ }^{4}$ The necessity of the conclusion is conditioned in that it depends on its premise - as Kant himself writes, it is necessary «under a condition» (Kant [1800]: 120; 615): it is not necessary in itself, but as conclusion of the inference of which it is part.

${ }^{5}$ This modal aspect is for Kant so central to the notion of syllogism to be part of its definition: «an inference of reason [a syllogysm] is the cognition of the necessity of a proposition through the subsumption of its condition under a given universal rule» (Kant [1800]: 120; 614). The centrality of this link between syllogism, necessity and reason is confirmed also by the role it plays in Kant's distinction between the different degrees of cognition (see Rumore [2007]: 235-266), as well as to his understanding of science (see Capozzi [2002]: 541-541). See also Kant (1781/1787): A332/B389.
}

assume that when the conditioned is given, then so is the whole series of conditions subordinated one to the other, which is itself unconditioned, also given (i.e., contained in the object and its connection). Such a principle' of pure reason, however, is obviously synthetic; for the conditioned is analytically related to some condition, but not to the unconditioned. (Kant [1781/1787]: A307-8/B364)

This passage contains various elements that explain the relation between reason's search for unity, ideas, and the corresponding need of representing things in a certain way. First 1), the unification under principles is something that is prescribed by reason itself for any given judgement - for any given judgement, reason prescribes us to find a principle to which it can be brought back. As Kant himself explains, the fact that this prescription applies to any judgement makes this search for principles 2 ) a reiterative process: given this prescription, any new-found principle is again subjected to the same search for a higher principle under which to bring it.

This is for Kant directly bound with 3 ) the idea of the unconditioned. Indeed, in prescribing to always repeat the search for principles, we not only represent a certain set of judgements as grounded in a yet to find higher one, but we represent this yet to find higher principle as itself grounded in some other. Accordingly, to prescribe a reiterative search for principles directly amounts to represent these higher judgements as a series, the series of all these judgements a parte priori: this whole of judgements is what Kant refers to as the unconditioned. It is here not necessary to understand what unconditioned precisely means, nor to consider whether such a series is taken to be infinite or finite: what is important is that the link between the search for principles and the representation of the unconditioned - i.e. of the whole series - directly explains 3.1) why reason's maxim is bound to a certain representation of things as well as 3.2) how the logical use of reason generates transcendental ideas ${ }^{6}$.

${ }^{6}$ For an analysis of this passage which deals extensively also with the notion of unconditioned see the impressive 
Concerning the first point 3.1), the link between reason's maxim and a certain representation of things somewhat trivially depends on the fact that, for Kant, our concepts have a certain objectivity, i.e. they represent certain features of things. Accordingly, if a maxim prescribes to find a higher principle accounting for different elements (e.g. why various substances melt as the temperature increases), we are thereby representing the objects themselves (in this case, the melting substances) as governed by such a yet to find principle (e.g. a certain law), and accordingly as having the property described by it. Given the aforementioned recursive nature of the maxim of reason and its link with the idea of a totality of higher principles, it is clear that the prescription in question immediately amounts to the representation of things as governed by an analogously (i.e. hierarchically) ordered system of rules, which are expressed by the various judgements making up the whole series.

This makes it easy to understand the various parallelisms that Kant draws between logical and transcendental principles at the end of the Dialectic, where he deals specifically with those maxims that he will later ascribe to the power of judgement - for instance, when he claims that «the logical principle of genera therefore presupposes a transcendental one if it is to be applied to

Willaschek (2018). The most relevant difference between Willaschek's interpretation and the one proposed here lies in the understanding of Kant's distinction between the logical and real use of reason. Whereas Willaschek (2018): 48-49 takes this difference to lie in the relation with an object - the logical use of reason is formal in that it abstracts from any relation with the represented object, while the real does not - I take Kant's distinction to still be the same he introduced in his dissertation (see Kant [1770]: 393; 385): the logical use of reason simply establishes new relations between otherwise given representations - in the case of reason, it produces syllogisms from given judgements - the real use of reason, instead, involves the production of new representations (specifically, the ideas). For a more detailed defence of this understanding of this interpretation of the distinction between logical and real use of reason in its relation with the genesis of ideas, see my Sala (2018a). nature» (Kant [1781/1787]: A654/B682). Indeed, if our principles are understood as rules representing general features of things, and are thought of as hierarchically ordered under one another, in searching for higher principles we are in fact representing things as governed by similarly hierarchically ordered rules. It is in this sense that the application of the logical principle presupposes a transcendental one: in our search for higher principles, we are representing nature in a certain way, without this being anyhow grounded in the outcomes of this research - this way of representing things is already in place before any kind of higher law governing them is actually discovered ${ }^{7}$.

Secondly, the genesis of ideas 3.2) is similarly linked to the maxims of reason: ideas are for Kant precisely the representation through which we represent the series of judgement as a whole and, therefore, as unconditioned - for instance, in empirical psychology, we try to bring back the various capacities of the mind to some fundamental power, in that we take all of them to be the enacted by an absolutely unitary soul. It is here unnecessary to get into further details about the genesis of ideas. What is here important is that, as they are the representations through which we represent

${ }^{7}$ In this respect, the here proposed interpretation departs from the majority of the works on the topic: usually, a certain way of representing objects (e.g. as systematic, through ideas, etc.) is taken to be something which needs to be presupposed if some condition is to be met. For instance, McLaughlin takes certain assumptions to be necessary if our research is to be considered rational (McLaughlin [2014]; see also Guyer [1997]); Geiger (2003) for the amenability of the world to our research. Contrarily to this trend, I take this representation of nature to be immediately embedded in the research activity itself: to research general laws immediately amounts to represent nature in a certain way, and the necessity of this kind of representation does not depend on some further condition. Zuckert (2017): 98-106 seems to come closer to this picture, in that she takes transcendental ideas to be the direct correlate of our research activity. However, in contrast to the here proposed reading, she does not seem to think the same about those transcendental principles which will later become the maxims of the power of judgement. 
the series of judgements as unconditioned, they immediately result from what is prescribed by the logical maxim of reason, for as we have seen, the latter's prescription involves the representation of the pro-syllogistic chain as unconditioned ${ }^{8}$.

Before turning to the Dialectic's deduction, it is necessary to briefly mention one last 4) element of the quoted passage, i.e. Kant's reference to the giveness of the unconditioned. Indeed, this is what discriminates between the regulative, legitimate use of ideas and their constitutive, dialectical one. As mentioned above, through ideas we represent the series of judgements as an unconditioned whole, and accordingly also the things in the world as having a certain order (e.g. as created by God). Although, as shown above, to represent things in this way is for Kant immediately bound with the search for higher principles, this does not imply that the objects represented by these ideas (God, soul and the world) are actually given: we just represent things as if they were in relation to them in our search for principles. Accordingly, although it is for Kant unavoidable to represent things according to ideas in our search for higher principles - which is what their regulative use amounts to this does not mean that we can actually know the objects of ideas, nor that we can employ their representations the other way round: we cannot use them as constitutive principles, i.e. as principles for syllogisms in which they are the determining grounds for drawing conclusions about the objects that we represented as in relation to the object represented by the idea. For instance, although it is for Kant unavoidable to represent the whole of reality as grounded in a supreme being, this does not mean that we can actually know God, nor that we can draw conclusions about things in that we take them as grounded in God (e.g. we cannot conclude that our world is the best possible in that it was created by a supremely wise and good being) ${ }^{9}$.

\footnotetext{
${ }^{8}$ For an in-depth analysis of the genesis of ideas see Sala (2018a) and Caimi (2013).

${ }^{9}$ On the giveness of the unconditioned, see the aforementioned Willaschek (2018). On the regulative use of ideas, see Ferrarin (2012): 49-55.
}

\section{THE TRANSCENDENTAL DEDUCTION OF THE IDEAS IN THE FIRST CRITIQUE}

Against this background, it is possible to briefly reconstruct Kant's deduction of the transcendental ideas in the Dialectic. As made popular by Henrich (1989), Kant uses the term deduction according to the juridical meaning of his times. In this context, deduction indicated the legal procedure inquiring into the legitimacy of some possession by taking into account the relevant facts: for instance, a deduction could be necessary for establishing whether someone's claim over a certain land was legitimate or not, and the dispute could be set (e.g.) by providing the deed of sale. In the Critique of pure Reason, this disputed possession is a priori knowledge and, in the case of the Transcendental Dialectic, that through ideas. However, in this latter, Kant's references to the notion of a transcendental deduction are not as common as they were in the Analytic, and only one of them is relevant here:

Now, if one can show that although the three kinds of transcendental ideas (psychological, cosmological and theological) cannot be referred directly to any object corresponding to them and to its determination, and nevertheless that all rules of the empirical use of reason under the presupposition of such an object in the idea lead to systematic unity, always extending the cognition of experience but never going contrary to experience, then it is a necessary maxim of reason to proceed in accordance with such idea. And this is the transcendental deduction of all the ideas of speculative, not as constitutive principles for the extensions of our cognition to more objects than experience can give, but as regulative principles for the systematic unity of the manifold of the manifold of empirical cognition in general, through which this cognition, within its proper boundaries, is cultivated and corrected more than could happen without such ideas, through the mere use of the principles of understanding. (Kant [1781/1787]: A671/B699, amended translation)

In this passage, Kant explicitly mentions a transcendental deduction of the ideas and says 
that what he has just explained - this (dieses) - is what such a deduction amounts to. The long sentence coming before this remark contains two main claims. The first claim is that ideas «cannot be referred directly to any object corresponding to them and to its determination». This is the Transcendental Dialectic's negative result which was mentioned as a last point in previous section 4): the objects represented in the ideas cannot be given to us and, in this sense, they have no reference - they are not objects of a possible experience and it is therefore impossible for us to have any knowledge of them. More than a transcendental deduction, this claim seems to be the (negative) outcome of such a justification procedure: reason's claim to be in possession of a metaphysical knowledge of the world, God and the soul is refuted on the grounds of the lack of an adequate ground for justifying it.

The second claim is that the presupposition of the "object in the idea lead[s] to systematic unity» and, because of this «it is a necessary maxim of reason to proceed in accordance with such an idea». For what concerns the expression «object in the idea», this is something which Kant introduces some lines above the quoted passage. For something to be given "as an object in the idea» (Kant [1781/1787]: A670/B98) means that "no object is given $[. .$.$] but which serves only to represent oth-$ er objects to us, in accordance with their systematic unity, by means of the relation to this idea, hence to represent these objects indirectly» (ibid.). This, however, is nothing other but the mechanism which we have pointed out as the fourth and last point in the previous section: although we are not given the objects represented in the ideas (e.g. God), we nonetheless represent things as if these objects were given and, specifically, as if the things which we actually know were in relation to them as their ultimate ground. Similarly, what we have seen in the previous section also explains why to do so constitutes a necessary maxim of reason: to represent things as grounded in something unconditioned was in fact a direct consequence of reason's prescription of a complete unification of our knowledge under principles, because to search for this unity immediately amounts to represent things in such a way.

This clearly cannot constitute a transcendental deduction like the successful one of the categories or the unsuccessful one of the first considered claim (i.e. those of transcendent metaphysics), for there is no claim to be in possession of a knowledge of some object. Nonetheless, it seems to fit the aforementioned legal meaning of deduction, in that it answers a question of right: a certain way of representing of things, that to ideas, is explained to have in fact a legitimate use - ideas have a legitimate use as regulative principles for the investigation of phenomena, for searching for principles under which to unify the cognitions that we already have. In this way, this deduction importantly differs from that of the pure concepts of the understanding, in that it does not involve showing how, without certain representation, a certain activity would not be possible: the logic at play is a much more linear, in that Kant simply shows that to search for the unity of our principle directly amounts to represent nature as unitary.

\section{THE CONTENTS AND THE LOGIC OF THE PRINCIPLE OF PURPOSIVENESS OF NATURE}

In this section I will show how the logic behind Kant's introduction of the principle of purposiveness of nature in the third Critique and its presentation as necessary closely resembles that of ideas (as reconstructed in the previous sections): also in this case, a certain way of representing nature is immediately bound with a certain search activity (respectively: the representation of nature as purposive for our cognitive faculties and reflecting judgement).

Both the principle of purposiveness of nature and the notion of a reflecting power of judgement (together with that of determining power of judgement) are novelties introduced in the third Critique $^{10}$. In particular, the third Critique's distinction between reflecting and determining power of

\footnotetext{
${ }^{10} \mathrm{On}$ the discovery of the principle of purposiveness, see
} Zammito (1992): 89-105 and 151-177. 
judgement further specifies the first Critique's role of Urteilskraft (of mediating between the particular and the universal, see e.g. Kant [1781/1787]: A132/B171) by distinguishing between two ways in which these two can be related. When the universal (the concept) is already given and the power of judgement simply subsumes the particular under it, the power judgement is determining (see Kant [1790]: 179; 67), when the concept under which the particular falls is not yet available and we therefore need to find it, the power of judgement is reflecting - as Kant himself writes, its role is that "of ascending from the particular in nature to the universal» (Kant [1790]: 180; 67), and it aims to «the unity of all empirical principles under equally empirical but higher principles» (Kant [1790]: 180; 67).

In this respect, Kant's distinction between the reflecting and determinant power of judgement presents an important similarity with the two different uses of reason which, as we have seen in the previous section, Kant dealt with in the Transcendental Dialectic of the first Critique. In it, Kant factually attributed two different kinds of activity to reason: both drawing inferences when the principles are available and finding principles under which to group other judgements. The distinction between determining and reflecting power of judgement seems to replicate the same logic: in one case the concept (or the principle) is given, and the role of the faculty is, respectively, to subsume the particular under the universal or drawing the inference; in the other, opposite case, the concept (or principle) is not given, and reason or judgement aims to find them ${ }^{11}$.

\footnotetext{
${ }^{11}$ In this respect, it is important to point out a fundamental difference between the activity ascribed to reason in the first Critique and the one attributed to reflecting judgement in the third. Whilst reason's activity was completely severed from intuition - what it systematised were judgements and concepts (see Kant [1781/1787]: A306/B364 and A302/B359) - the reflecting power of judgement deals directly also with intuition: its business includes also «finding the universal for the particular that is offered to it by perception» (Kant [1790]: 186; 72). The historical reasons for this change of ascription are to be
}

The principle of purposiveness of nature is introduced by Kant as a principle through which we represent nature «as if an understanding contained the ground of the unity of the manifold of its empirical laws» (Kant [1790]: 181; 68). What this means is explained in two ways. First a), through this principle, we are said to represent nature as «suitab[le] for human understanding in its necessary business of finding the universal for the particular that is offered to it by perception and then further connection in the unity of the principle for all that is different (though universal for each species)»(Kant [1790]: 186; 72). Secondly, b) the principle of purposiveness of nature is said to be «expressed in the maxims of the power of judgement» (Kant [1790]: 184; 71), which are what in the first Critique were called maxims of reason (see Kant [1781/1787]: A666/B694) and comprehend all those laws like the lex continui (see Kant [1790]: 182; 69; Kant [1781/1787]: A661/B689) and Ockham's razor (see Kant [1790]: 182; 69; Kant [1781/1787]: A652/B680), which regulate our empirical investigation of nature.

Kant's explanation of the purposiveness of nature as a suitability for our cognitive business (a) presents an important similarity with the logic behind the first Critique's explanation of the genesis and the necessity of representing things through ideas. Indeed, as we have seen in the previous section, the fundamental element at the root of the genesis of this necessity was also a task, and specifically that task of searching for higher principles which is now taken to be one of the two cognitive tasks now ascribed to reflecting judgement. A certain way of representing things was in fact the immediate consequence of what was reason's prescription - to search for something (i.e. a certain unity) directly amounted to represent nature as having a yet to find unity of this kind. The dependency on a cognitive goal of

traced back to Kant's work on his theory of the beautiful, and in particular to the link between beauty and purposiveness and the contextual discovery of reflective judgement: on this, Zammito (1992): part one and Sala (2018b). 
a certain representation of nature was also explicitly acknowledged by Kant in his definition of reason's maxims as «subjective principles that are taken not from the constitution of the object but from the interest of reason in regard to a certain possible perfection of the cognition of this object» (Kant [1781/1787]: A666/B694, my emphasis). In this respect, the fundamental difference is that, whereas in the first Critique purposiveness was left implicit - nature was taken to have a certain kind of unity in conformity with a certain cognitive end, but this unity was not directly explained in teleological terms - in the third Critique the representation of nature is spelled out directly in teleological terms, and further specified only later, by spelling out what this conformity entails.

This brings us to the second b) explanation of the principle of purposiveness of nature, i.e. that in terms of the maxims of judgement. Differently than in the first Critique, Kant does not deal with these maxims in much detail: he simply mentions three of them (but implies that there are others by terminating the list with an etc.), and then claims that they are "the basis for research into nature» (see Kant [1790]: 182; 69) ${ }^{12}$. Also in this case, Kant's considerations about these same maxims from the first Dialectic make it clear what the link between these maxims and the notion of purposiveness is: as seen above, a certain way of representing nature (i.e. according to these maxims) is a direct consequence of a certain cognitive task (an «interest»), so that to represent nature according to them factually is to represent it as conforming to this task, that is, as conforming to our cognitive goals ${ }^{13}$.

\footnotetext{
${ }^{12}$ Although he does not mention the first Critique in his explanation, Allison (2001): 30-34 offers a similar interpretation of these maxims.

${ }^{13}$ The fact that, in the first Critique, Kant considers also the ideas to be necessary for this research activity clearly raises the question of how he later conceived of the relation between reflective judgement and transcendental ideas. To answer this question, however, falls beyond the scope of my paper.
}

\section{THE TRANSCENDENTAL DEDUCTION OF THE PRINCIPLE OF PURPOSIVENESS}

In view of the foregoing sections, it is finally possible to give an account of the transcendental deduction of the principle of purposiveness of nature. As he did in the Transcendental Dialectic for the ideas, also in this case Kant does not dwell long on the transcendental deduction of the principle of purposiveness, and deals with it just in one section of the Introduction, the fifth ${ }^{14}$. After stating that the principle of purposiveness of nature is expressed in the maxims of the power of judgement and that it needs a transcendental deduction, Kant lays out some remarks which, one page later, he retrospectively declares to be such a deduction (See Kant [1790]: 184; 71).

In particular, Kant begins by stating how the laws of nature in general (i.e. those expresses in the principles of pure understanding) are not the sole laws of nature: there are also the empirical laws, i.e. the laws of nature that we discover empirically. Kant makes then two observations on these latter laws: on the one hand, as we know them only a posteriori, there is a distinct sense in which they are contingent - experience does not give us any insight into the necessity of what its known through it, so that, in this sense, these laws are not known as necessary. On the other, precisely because we conceive them as laws, we take these empirically discovered laws to nonetheless be necessary $^{15}$. Following these considerations, he writes:

\footnotetext{
${ }^{14}$ As it will become evident in the body of the text below, I believe that the portion of text which Kant himself indicates as the transcendental deduction of the principle of purposiveness of nature contains an argument which is on its own sufficient for answering the question of the legitimacy of such a principle. Therefore, it seems to me unnecessary to assume, as often done (see e.g. Allison [2001]: 38; Teufel [2017]: 110), that the transcendental deduction of this principle is more extended in the text than what Kant explicitly states.

${ }^{15}$ For the moment, it is unnecessary to opt for a particular interpretation of this notion of necessity. In the following I will argue that, despite what one might thing at first sight, the necessity in question is not the nomic necessity of the law, but its conceptual necessity as the specification
} 
with regard to them [the empirical laws] we judge the unity of nature in accordance with empirical laws and the possibility of the unity of experience (as a system in accordance with empirical laws) as contingent. But since such a unity must still necessarily be presupposed and assumed, for otherwise no thoroughgoing interconnection of empirical cognitions into a whole of experience would take place, because the universal laws of nature yield such an interconnection among things with respect to their genera, as things of nature in general, but not specifically, as such and such particular beings in nature, the power of judgment must thus assume it as an a priori principle for its own use that what is contingent for human insight in the particular (empirical) laws of nature nevertheless contains a lawful unity, not fathomable by us but still thinkable, in the combination of its manifold into one experience possible in itself. Consequently, since the lawful unity in a combination that we cognize as in accordance with a necessary aim (a need) of the understanding but yet at the same time as contingent in itself is represented as a purposiveness of the objects (in this case, of nature), thus the power of judgment, which with regard to things under possible (still to be discovered) empirical laws is merely reflecting, must think of nature with regard to the latter in accordance with a principle of purposiveness for our faculty of cognition, which is then expressed in the maxims of the power of judgment given above. (Kant [1790]: 183-185; 70-71)

This passage is made problematic by the fact that, in it, Kant resorts to the notions of «unity of experience» and "unity of nature», which he does not explain. However, whatever these might mean, the structure of the argument is clear - it explains the necessity of adopting the principle of purposiveness of nature, and is structured in the following way:

I. If the laws of nature are regarded as contingent, the unity of nature is to be regarded as contingent II. If the unity of nature is regarded as contingent, the unity of experience is not possible

III. But the unity of experience must be possible IV. $\therefore$ (I, II, III): Nature must be conceived as con-

of a more general law. taining a lawful unity even though we have no insight into the necessity of empirical laws.

$\mathrm{V}$. What is contingent and is in accordance with an aim is purposive

VI. The lawful unity of nature is in accordance with an aim of the understanding

VII. $\therefore$ (V, VI) The lawful unity of nature is purposive with respect to the aim of the understanding VIII. $\therefore$ (IV, VII) Nature must be conceived as purposive with respect to our cognitive goals

IX. What it means to be conceived as purposive is expressed by the maxims of judgement.

As mentioned above, Kant does not explain what he means by «unity of experience» and «unity of nature», so that the meaning of Kant's argument is not immediately transparent. In particular, without reconstructing the meaning of unity of experience and unity of nature is not possible to give an account of Kant's argument. Nonetheless, there are three important lessons that can already be drawn from it.

First, a) from the structure of the argument, it is clear that, if the first part (I-IV) of the argument is to be valid, for nature to have a "unity» must be equivalent with it containing a "lawful unity».

Secondly, b) the lawfulness of this unity is put in contrast with the contingency of the empirical laws. In particular, the fact that Kant (IV) writes that we have to think nature as «lawful» despite we do not have any insight into the necessity of the empirical laws seems to imply that, b1) had we known the laws a priori (and therefore had an insight in their necessity), nature would have been known to have this lawful unity. Similarly, also the converse seems to hold: b2) to know nature's lawful unity would mean to have an insight in the necessity of empirical laws.

Third, c) most importantly, Kant's claim that to conceive nature as having a lawful unity is to conceive it as purposive (VI), when combined with his last claim (IX) - i.e. that to think of nature as purposive is to think of it according to the maxims of judgement - tells us that to conceive nature as having a lawful unity is to conceive it according to the maxims of judgement. 
Now, as seen above (section 3), to conceive nature according to the maxims of judgement was to conceive it as a hierarchically ordered system of genera and species. In this way, as seen in section one, we take all our concepts and cognitions to be unifiable by being brought back to higher ones (i.e. by finding their principles). Therefore, e) the unity of nature, the "lawful unity" Kant is referring to in the deduction, must be taken to be the same one of the maxims of judgement, i.e. nature as a system of genera and species.

This is in turn decisive for understanding Kant's reference to the particular laws of nature and their necessity. Indeed, as mentioned above, Kant's argument seems to imply that, were we to know nature's lawful unity, we would have an insight into the necessity of empirical laws in question. However, given that, as we have seen, the lawful unity in question is the unity of nature as a system of genera and species, this means that, were we to have an insight into this unity, we could derive all the particular empirical laws $a$ priori, from what we would know to be their principles. Accordingly, the necessity at stake in the transcendental deduction of the principle of purposiveness is not so much the nomic necessity of the empirical laws of nature, but their necessity as part of the lawful unity of nature, and accordingly as the necessary consequences of higher laws: as illustrated in the first Critique for syllogisms, also in this case a judgement and what it expresses are known as necessary by bringing them back to a principle.

Lastly, the fact that nature's lawful unity is identified with the unity of nature as a system of genera and species helps us clarifying also how the unity of experience on which the argument hinges is to be understood, and the sense in which it is necessary. First, given how the principle of purposiveness of nature is expressed by the maxims of judgment and how this principle is a condition of possibility of this unity of nature, this unity of experience is to be understood as the systematic unity of our empirical cognitions which we have dealt with in section 1 and 3: that is, as the unity of our empirical cognitions under principles. Sec- ondly, this makes in turn clear the sense in which this unity is necessary: not so much in that, without it, experience is not possible, but inasmuch as it is a prescription of our cognitive faculty themselves. In particular, the search for a systematic (i.e. complete) unity of our cognitions that, in the first Critique, was a consequence of our reason's prescription to find higher principles to unify our cognitions, is in the $K U$ ascribed to reflective judgement, and spelled out in terms of universals and particulars.

Against this background the transcendental deduction of the principle of purposiveness of nature seems to closely resemble the mechanism which was already present in the Transcendental Dialectic of the first Critique: a certain way of representing nature is entangled with a cognitive goal that, for Kant, is embedded in our faculties. In particular, the goal in question is to organize our cognitions in a completely systematic way. Although in the $K U$ Kant does not dwell long in explaining why he takes this to be an intrinsic cognitive goal, it seems possible to explain this in analogy with the $K r V$ : there, the goal of organizing our cognitions in a system was a direct consequence of the reiteration of the more basic goal of unifying them under principles, and this applies also to the $K U$ and reflective judgement's prescription to find a universal for any particular (see section 3 ).

Secondly, this cognitive goal directly implies a certain representation of nature: to aim for a systematic unity of our empirical cognitions means to represent nature (i.e. the things represented by these cognitions) as analogously organized, that is: as a system of genera and species (see section $1,3)$. In the deduction's text, this is conveyed by the aforementioned passages I-IV: if the "unity of experience» (i.e. a system of empirical cognitions) is to be "possible», what is cognized needs to be a «lawful unity» (i.e. organized in a systematic way). Moreover, as to represent nature as such a system is to represent nature in conformity with our cognitive goals, to represent it in this way means to represent it as purposive for our cognitive faculty.

Like the one of ideas in the Transcendental Dialectic, also this Deduction shows the necessity 
of a certain representation of nature only in relation to a specific cognitive goal, which is not in itself a condition of possibility of experience. As a consequence, also in this case, Kant's argument does not prove that nature is in a certain way (in this case, purposive for our cognitive faculties): it proves only that it is legitimate for to represent nature as being in a certain way in our search for yet to find universals. Accordingly, also in this case, the way of representing nature which is dealt with in this transcendental deduction is legitimated only as a regulative principle and not as a constitutive one: we are legitimated to research the laws of nature as if nature were purposive for our cognitive faculty (i.e. systematic), but we are not legitimated to use this representation of nature as a principle for determining any object.

\section{REFERENCES}

Allison, H., 2001: Kant's Theory of Taste, Cambridge University Press, Cambridge.

Caimi, M., 2013: Zur Metaphysischen Deduktion der Ideen in der Kritik der reinen Vernunft, "Methodus" 7, pp. 23-41.

Capozzi, M., 2002: Kant e la logica, Vol. I, Bibliopolis, Napoli.

Ferrarin, A., 2015: The Powers of Pure Reason. Kant and the Idea of Cosmic Philosophy, University of Chicago Press, Chicago-London.

Geiger, I., 2003: Is the Assumption of a Systematic Whole of Empirical Concepts a Necessary Condition of Knowledge?, "Kant-Studien" 94, pp. 273-298.

Ginsborg, H., 2015: The Normativity of Nature: Essays on Kant's Critique of Judgement, Oxford University Press, Oxford.

Guyer, P., 1997: Kant and the Claims of Taste, Cambridge University Press, Cambridge.

Guyer, P., 2003: Kant on the Systematicity of Nature: Two Puzzles, "History of Philosophy Quarterly” 20, pp. 277-295.

Henrich, D., 1989: Kant's Notion of a Deduction and the Methodological Background of the First Critique, "Kant's Transcendental Deductions", ed. by Eckart Förster, Stanford University Press, Stanford, pp. 29-46.

Kant, I., 1770: De mundi sensibilis atque intelligibilis forma et principiis, in Kants Gesammelte Schriften, ed. by Königlich-Preussische (then: Berlin-Brandenburgische) Akademie der Wissenschaften, 29 voll., vol. II, de Gruyter, Berlin, 1912, pp. 385-419; transl. and ed. by D. Walford and R. Meerbote, Concerning the Form and the Principles of the Sensible and Intelligible World (The Inaugural Dissertation), in The Cambridge Edition of Works of Immanuel Kant, Theoretical Philosophy, 1755-1770, Cambridge University Press, Cambridge, 1992, pp. 377-426.

Kant, I., 1781/1787: Kritik der reinen Vernunft, Erste Auflage, in Kants Gesammelte Schriften, ed. by Königlich-Preussische (then: BerlinBrandenburgische) Akademie der Wissenschaften, 29 voll., vol. IV, de Gruyter, Berlin, 1903, pp. 1-252; Zweite Auflage, vol. III, de Gruyter, Berlin, 1904; transl. and ed. by P. Guyer and A.W. Wood, Critique of Pure Reason, The Cambridge Edition of Works of Immanuel Kant, Cambridge University Press, Cambridge, 2000.

Kant, I., 1790: Kritik der Urteilskraft, in Kants Gesammelte Schriften, ed. by Königlich-Preussische (then: Berlin-Brandenburgische) Akademie der Wissenschaften, 29 voll., vol. V, de Gruyter, Berlin, 1913, pp. 165-485; transl. by P. Guyer and E. Matthews, Critique of Power of Judgment, The Cambridge Edition of Works of Immanuel Kant, ed. by P. Guyer, Cambridge University Press, New York, 2002.

Kant, I., 1800: Immanuel Kants Logik, ed. by G.B. Jäsche nach Vorlesungsskripten und Notizen, in Kants Gesammelte Schriften, ed. by Königlich-Preussische (then: Berlin-Brandenburgische) Akademie der Wissenschaften, 29 voll., vol. IX, de Gruyter, Berlin, 1923, pp. 1-150; transl. by M. Young, in Lectures on Log$i c$, The Cambridge Edition of Works of Immanuel Kant, Cambridge University Press, New York, 1992, pp. 527-640.

McLaughlin, P. 2014: Transcendental Presuppositions and Ideas of Reason, "Kant-Studien" 105, pp. 554-572. 
Meier, G.F., 1752 (2016): Auszug aus der Vernunftlehre. Halle Translated by Aaron Bunch, edited by Lawrence Parternack; Pablo Muchnik, Excerpt from the Doctrine of Reason, Bloomsbury, London.

Rumore, P., 2007: Lordine delle Idee. Le genesi del concetto di rappresentazione in Kant attraverso le sue fonti wolffiane (1747-1787), Le Lettere, Firenze.

Sala, L. 2018a: Uso logico e uso reale della ragione: origine e ruolo regolativo delle idee, "Con-Textos Kantianos" 8, pp. 303-318.

Sala, L., 2018b: Verso una critica della capacità di giudizio: del Gusto come questione critica. "Lestetica tedesca da Kant a Hegel", a cura di L. Filieri, M. Vero, ETS, Pisa.

Teufel, T., 2017: Kant's Transcendental Principle of Purposiveness and the "Maxim of the Lawfulness of Empirical Laws", in Massimi, M., Breitenbach, A. (eds.), Kant and the Laws of Nature, Cambridge University Press, Cambridge, pp. 108-127.

Vanzo, A., 2012: Kant e la formazione dei concetti. Verifiche, Trento.

Willaschek, M., 2018: Kant on the Sources of Metaphysics: The Dialectic of Pure Reason, Cambridge University Press, Cambridge.

Zammito, J., 1992: The Genesis of Kant's Critique of Judgment, University of Chicago Press, Chicago.

Zuckert, R., 2017: Empirical Scientific Investigation and the Ideas of Reason, in Massimi, M., Breitenbach, A. (eds.), Kant and the Laws of Nature, Cambridge University Press, Cambridge, pp. 89-107. 